\title{
Aluminium-Eriochrome Cyanin R, A Novel Chromogen for the Spectrophotometric Determination of Pentoprazole Sodium
}

\author{
Pavan Kumar GVSR, Kondrotu Srinivasa Rao \\ Department of Chemistry, MVGR College Of Engineering (A), Vizianagaram-535005, Andhra Pradesh. INDIA.
}

\begin{abstract}
A Spectrophotometric method for the determination of pentoprazole sodium in bulk and pharmaceutical formulations was developed by the authors. The method is based on the color reaction between the sample solution of the drug and a solution of aluminiumeriochrome cyanin $R$. the reagent was found to be unique and novel in the detection and determination of the drug. A reddish purple color solution is the resultant of the reaction between the drug and the reagent. This reddish purple colored product showed $\lambda_{\max }$ at $533.5 \mathrm{~nm}$. Beer's law was found to be obeyed in the concentration range 3.2-12.8 $\mu \mathrm{g} \mathrm{ml}^{-1}$. Limit of detection was found to be $0.048 \mu \mathrm{g} \mathrm{ml}^{-1}$ and limit of quantification was $0.148 \mu \mathrm{g}$ $\mathrm{ml}^{-1}$. The method was found to be sensitive, simple, easy, accurate and precise.
\end{abstract}

Key words: Pentoprazole Sodium, Eriochrome Cyanin R, Spectrophotometry, Pharmaceutical Formulations, Aluminium Chloride.

\section{INTRODUCTION}

Pantoprazole, sold under the brand name Protonix among others, is used for short-term treatment of erosive esophagi is associated with gastro esophageal refluxing disease (GERD), maintenance of healing of erosive esophagitis, and pathological hyper secretory conditions including Zollinger-Ellison Syndrome. ${ }^{1}$ Pantoprazole is a proton pump inhibitor drug that inhibits gastric acid secretion. It works on gastric parietal cells to irreversibly inhibit $(\mathrm{H}+/ \mathrm{K}+)$-ATP functions and suppresses the production of gastric acid. ${ }^{1,2}$ Adverse effects of pentoprazole include pneumonia, ${ }^{3}$ abdominal pain, diarrhea, flatulence, nausea, vomiting headache, dizziness, arthralgia , dry mouth, low white blood cell count, interstitial nephritis, Stevens-Johnson syndrome. ${ }^{1}$ Osteoporosis and bone fracture have been observed in patients on high-dose and/or long term prescription proton pump inhibitors. ${ }^{4}$

Assay of the drug is important in view of the adverse affects of it on human health due to long term usage or over dosage. It was reported in literature ${ }^{5-15}$ that, the quantitative determination of the drug was performed by HPLC, HPTLC, UV methods. Some researchers reported extractive Spectrophotometric methods for the determination. These methods were found to involve tedious and laborious procedures, non economical and indeterminate to accuracy. During the course of study of color reactions between the drug solution and reagents, it was found that, aluminium-eriochrome cyanine $\mathrm{R}$ on reaction with the drug, exhibited an instantaneous, stable, clear reddish purple color. The detailed procedure for the determination of the drug using aluminium eriochrome cyanin $\mathrm{R}$ is presented.

\section{MATERIALS AND METHODS}

All reagents used were of analytical grade. Double distilled water was used throughout the experiment.
Submission Date: 18-01-2017; Revision Date: 02-03-2017; Accepted Date: 14-03-2017

DOI: 10.5530/ijper.51.2s.47 Correspondence: G V S R Pavan Kumar, Address: department of Chemistry, MVGR College of engineering $(A)$, Vizianagaram-535005, Andhra Pradesh, INDIA. Phone no: 9989206996 E mail: prs_ganti@yahoo. co.in

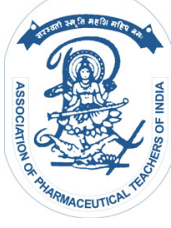

www.ijper.org 


\section{Preparation of aluminium chloride solution:}

A solution of aluminium chloride of concentration $1 \times 10^{-3} \mathrm{M}$ was prepared by dissolving an adequately weighed quantity of the solid in distilled water and the solution was made up to the mark.

\section{Preparation of eriochrome cyanin $\boldsymbol{R}$ solution}

A solution of eriochrome cyanin $\mathrm{R}$ of concentration $1 \times 10^{-3} \mathrm{M}$ was prepared by dissolving an adequately weighed quantity of the dye in distilled water and the solution was made up to the mark.

\section{Preparation mixed reagent aluminium-eriochrome cyanin $R$}

Equal volumes of aluminium chloride solution and eriochrome cyanin $\mathrm{R}$ solution were mixed to result a clear and stable purple color solution of aluiminumeriochrome cyanin R solution. Any precipitation was not found during the preparation of the mixed reagent.

\section{Preparation of pentoprazole sodium solution}

An adequately weighed quantity of the drug sample was dissolved in distilled water and filtered to remove suspended matter from the solution. The resulting solution was made up to the mark and standardized. ${ }^{16}$

\section{Preparation of commercial sample solution of the drug}

Ten tablets of the commercially available pentoprazole were ground in to a fine powder. From such powder adequate amount the sample was transferred into a $100 \mathrm{~mL}$ volumetric flask and dissolved in distilled water. The resulting solution was filtered and made up to the mark.

\section{Instruments used}

All pH measurements were made using ELICO LI 120 pH meter. Absorbance measurements were carried out using JASCO V 750UV VISIBLE double beam spectrophotometer with matched set of quartz cuvettes $(10 \mathrm{~mm}$ thickness).

\section{Method}

\section{Recommended procedure for the determination of $\lambda_{\max }$}

An aliquot of the pure drug sample solution was transferred into a $50 \mathrm{ml}$ volumetric flask. To this $3 \mathrm{ml}$ of the aluminium-eriochrome cyanin $\mathrm{R}$ solution was added and mixed well. The resulting solution was made up to the mark using distilled water. Absorption spectrum for the resulting solution was recorded in the range 380$900 \mathrm{~nm}$. The resulting reddish purple colour solution showed a $\lambda_{\max }$ at $533.5 \mathrm{~nm}$ (Figure 1).
Recommended procedure for the determination of pentoprazole sodium

A series of solutions of the drug sample were prepared by transferring $1 \mathrm{ml}, 2 \mathrm{ml}, 3 \mathrm{ml}, 4 \mathrm{ml}$, and $5 \mathrm{ml}$ in to $50 \mathrm{ml}$ volumetric flasks. In each of the flasks $3 \mathrm{ml}$ of aluminium-eriochrome cyanin $\mathrm{R}$ reagent was added and mixed well. The resulting solution was made up to the mark using distilled water. A control blank solution was prepared by transferring $3 \mathrm{ml}$ of the reagent in a $50 \mathrm{ml}$ volumetric flask and made up to the mark using distilled water. Absorbance measurements were recorded for each of the colored solution at $533.5 \mathrm{~nm}$. A plot was drawn by taking concentration on abscissa and the corresponding $\Delta$ Abs values on ordinate (Figure 2 ). This plot represented a straight line passing through origin obeying Beer's law. From such a plot concentration of the drug in a given solution was calculated.

\section{Specificity}

The effect of excipients such as starch, lactose, magnesium stearate, titanium oxide and talc etc was evaluated to study the specificity of the proposed method through the analysis of a placebo solution. The developed method was applied to check the interference of any of

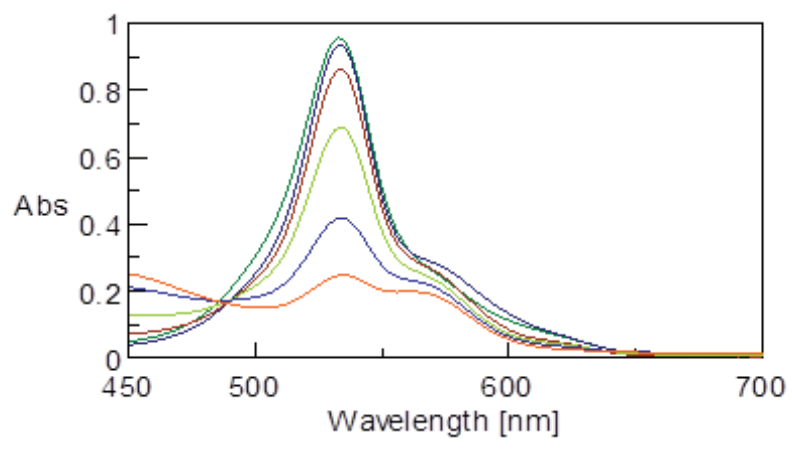

Figure 1: wavelength maximum spectrum for the reddish purple color reaction.

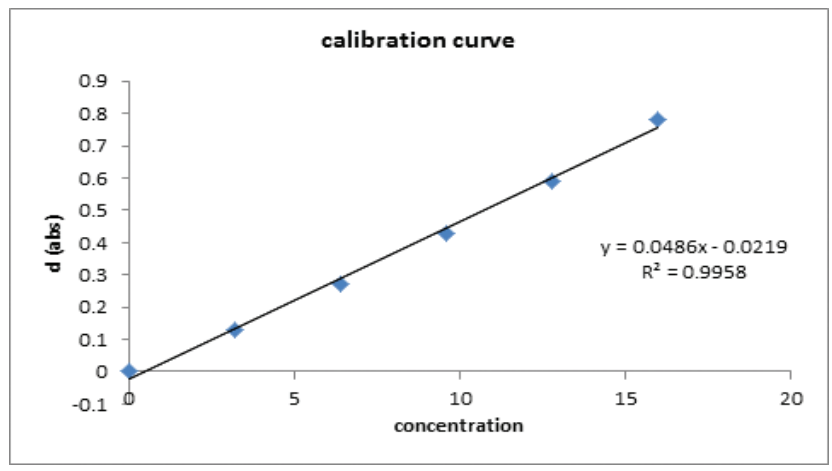

Figure 2: Beer's law plot for the red colored product obtained by the reaction between the drug and the reagent. 
the above mentioned substances with the absorbance of the sample solution.

\section{Linearity}

A stock solution of pentoprazole sodium was prepared and from such solution series of solutions by transferring adequate volumes of the drug solution to give a concentration range of $2-80 \mu \mathrm{g} / \mathrm{ml}$ were prepared. Each solution was prepared in triplicate and linearity was determined by constructing a plot between absorbance and concentration.

\section{Precision}

Intraday and inter-day precisions, as per standard guidelines were determined to assess the precision of the method developed by the authors. From such data the $\%$ RSD was calculated.

\section{Accuracy}

To the pre-analysed sample solutions, a known amount of standard stock solution was added at different levels, i.e. $80 \%, 100 \%$, and $120 \%$. The solutions were reanalyzed by the proposed method.

\section{Sensitivity}

The sensitivity of measurements of pentoprazole by the proposed method was determined by limit of detection (LOD) and limit of quantification (LOQ). The LOD and LOQ are calculated using $\mathrm{LOD}=3.3^{*} \mathrm{SD} /$ slope and $\mathrm{LOQ}=10 * \mathrm{SD} /$ slope.

\section{Ruggedness}

Ruggedness of the proposed method is determined for $60 \mu \mathrm{g} / \mathrm{ml}$ concentration of pentoprazole by analysis of aliquots by two analysts using same operational and environmental conditions.

\section{RESULTS AND DISCUSSION}

Complete spectral data for the colored product obtained by the reaction between pentoprazole and aluminiumeriochrome cyanin $\mathrm{R}$ was presented in Table 1 . Beer's law was found to be obeyed in the range 3.2-12.8 $\mu \mathrm{g} \mathrm{ml}^{-1}$. Table 4 depicts a comparison between the beer's law obedience of the proposed method with those of the methods found in literature. Molar extinction coefficient was found to be $11.4 \times 10^{4} \mathrm{M}^{-1} \mathrm{~cm}^{-1}$. Correlation coefficient was found to be 0.9997 . Limit of detection was found to be $0.048 \mu \mathrm{g} \mathrm{ml}^{-1}$ and limit of quantification was $0.148 \mu \mathrm{g} \mathrm{ml}^{-1}$.

\section{Chemistry of the reaction}

During the experimentation the following observations were noticed. Eriochrome cyanina $\mathrm{R}$ is a pale yellow colored solution. Such solution on mixing with aluminium chloride, a colorless solution, results a purple color solution. Drug sample solution of pentoprazole on reaction with the reagent, aluminium-eriochrome cyanin $\mathrm{R}$, fluoride in the drug will react with aluminium in the reagent and releases the dye eriochrome cyanin $\mathrm{R}$ into the solution. This results a decrease in intensity of the color solution. When series of varying concentrated solutions of the drug were prepared a liner decrease in the intensity of the color was observed.

Aluminium Chloride + Eriochrome cyanin $\mathrm{R} \rightarrow$ [aluminium-eriochrome cyanin R]

[Aluminium-eriochrome cyanin R] + Pentoprazole $\rightarrow$ eriochrome cyanin $\mathrm{R}+[\mathrm{Al}+\mathrm{drug}]$

The color intensity was found to be a linear decrease, change in absorbance was calculated. And it was found to be a linear increase. And hence a plot is drawn by taking concentration on abscissa and the corresponding change in absorbance on ordinate, a straight line passing through origin is the result obeying Beer's law. From such plot concentration of the drug in a given solution is calculated.

The concentration of aluminum chloride solution as well as eriochrome cyanin $\mathrm{R}$ solution was fixed as $1 \times 10^{-3} \mathrm{M}$. Below and above the optimum concentration level $\left(1 \times 10^{-3} \mathrm{M}\right)$, the absorbance measurements were found to be fluctuating and inaccurate.

Varying volumes of aluminium chloride and eriochrome cyanin $\mathrm{R}$ solutions were also tried to fix the concentration of the mixed reagent. It was found that mixing of equal volumes of the two solutions yields accurate absorbance measurements. Hence it was suggested to prepare the reagent by mixing equal volumes of aluminium chloride solution and eriochrome cyanin $\mathrm{R}$ solution. Addition of $3 \mathrm{ml}$ of the mixed reagent was found to be optimum for the reaction. Below and above such volume, the absorbance measurements were found to be inconsistent.

\section{Effect of $\mathrm{pH}$}

The reaction was studied in different acid media such as, hydrochloric acid, sulphuric acid, phosphoric acid, nitric acid, acetic acid. It was found that the reaction is not favored by acid media. The aluminium-eriochrome cyanin $\mathrm{R}$ complex was found to be unstable in acidic solutions. Hence it was suggested to avoid acid medium during the course of the reaction. The same reaction was also studied in alkaline media and found to be unfavorable. Hence a $\mathrm{pH}$ of 7 is advised for the present study.

Visible Spectrophotometric methods reported in literature for the determination of pentoprazole, were found 
to have tedious reaction procedures and use of organic solvents. These methods were found to be indeterminate to accuracy. The method developed by the authors was found to be sensitive compared to those reported in literature ${ }^{[6]}$ so far by visible spectrophotometry with respect to the LOD and LOQ values calculated,. The method developed by the authors is simple, easy, accurate, precise and advantageous.

\section{Application to commercial sample analysis}

In order to check the validity of the method proposed, pentoprazole was determined in some commercial samples. Table 2 gives a complete data about the determination, from which it is clear that there is a close agreement between the results obtained and the label claim. The results obtained were also statistically compared by Student's t-test for accuracy and variance ratio F-test for precision with those of the literature method. From these results it was found that the method proposed was accurate and precise as the results were well within the prescribed standard limits. Spike recovery tests were performed to study the validity of the method proposed. The results of recovery study were presented in Table.3.

\begin{tabular}{|c|c|c|}
\hline S.No & Parameter & Result obtained \\
\hline 1 & $\lambda_{\max }$ in $\mathrm{nm}$ & 533.5 \\
\hline 2 & Beer's law limits $\mu \mathrm{gml}^{-1}$ & $3.2-12.8$ \\
\hline 3 & Molar abosrptivity $\mathrm{M} \mathrm{cm}^{-1}$ & $11.4 \times 10^{4}$ \\
\hline 4 & Limit of detection, ${\mu \mathrm{gml}^{-1}}^{-1}$ & 0.04 \\
\hline 5 & Limit of quantification, $\mu \mathrm{gml}^{-1}$ & 0.14 \\
\hline 6 & Correlation coefficient & 0.9979 \\
\hline 7 & Regression equation & $Y=0.048 \times-0.021$ \\
\hline 7.a & Intercept & -0.021 \\
\hline 7.b & Slope & 0.048 \\
\hline
\end{tabular}

\begin{tabular}{|c|c|c|c|}
\hline Tablet brand name & Nominal amount & Standard method & Method developed \\
\hline \multirow[t]{3}{*}{ PAN } & \multirow[t]{3}{*}{$20 \mathrm{mg}$} & $100.3 \pm 0.51$ & $99.5 \pm 0.69$ \\
\hline & & & $t=2.11$ \\
\hline & & & $F=1.83$ \\
\hline \multirow[t]{3}{*}{ PENTOCIP } & \multirow[t]{3}{*}{$40 \mathrm{mg}$} & $99.6 \pm 1.01$ & $98.7 \pm 1.01$ \\
\hline & & & $t=1.90$ \\
\hline & & & $F=2.41$ \\
\hline \multirow[t]{3}{*}{ PENTOP 40} & \multirow[t]{3}{*}{$40 \mathrm{mg}$} & $100.1 \pm 0.62$ & $99.8 \pm 1.32$ \\
\hline & & & $t=2.43$ \\
\hline & & & $F=4.5$ \\
\hline
\end{tabular}

\begin{tabular}{|c|c|c|c|c|}
\hline \multirow{2}{*}{ Formulation studied } & $\begin{array}{c}\text { Amount of drug in } \\
\text { tablet }\end{array}$ & $\begin{array}{c}\text { Amount of pure drug } \\
\text { added }\end{array}$ & Total drug found & $\begin{array}{c}\text { Pure drug recovered } \\
\text { (\%) }\end{array}$ \\
\hline \multirow{2}{*}{ PENTOP 40 } & 4.99 & 2.5 & 7.49 & 100 \\
\cline { 2 - 5 } & 4.99 & 5 & 9.98 & 99.89 \\
\cline { 2 - 5 } & 4.99 & 7.5 & 12.48 & 99.9 \\
\hline
\end{tabular}

All the quantities used were in microgram level 


\begin{tabular}{|c|c|c|c|c|}
\hline S.No & Name of the authors & Beer's law obedience & $\begin{array}{c}\text { Beer's law obedience } \\
\text { for the method } \\
\text { proposed by the } \\
\text { authors }\end{array}$ & Ref. No \\
\hline 1 & Rajanish Kumar et al & $5-70 \mu \mathrm{g} / \mathrm{ml}$ & \multirow{9}{*}{$3.2-12.8 \mu \mathrm{g} / \mathrm{ml}$} & 5 \\
\hline 2 & M M Baraka et al & $10-50 \mu \mathrm{g} / \mathrm{ml}$ & & 10 \\
\hline 3 & O Z Devi et al & $\begin{array}{l}2.5-50 \mu \mathrm{g} / \mathrm{ml} \\
0.25-4 \mu \mathrm{g} / \mathrm{ml}\end{array}$ & & 6 \\
\hline 4 & Jigar Pandya et al & $5-25 \mu \mathrm{g} / \mathrm{ml}$ & & 14 \\
\hline 5 & M P Reddy et al & $50-300 \mu \mathrm{g} / \mathrm{ml}$ & & 12 \\
\hline 6 & Sahadev et al & $10-50 \mu \mathrm{g} / \mathrm{ml}$ & & 13 \\
\hline 7 & R Kalaichelvi et al & $10-50 \mu \mathrm{g} / \mathrm{ml}$ & & 15 \\
\hline 8 & SUSULU et al & $2.5-80 \mu \mathrm{g} / \mathrm{ml}$ & & 8 \\
\hline 9 & K Basavaiah et al & $\begin{array}{c}0.12-50 \mu \mathrm{g} / \mathrm{ml} \\
0.5-6 \mu \mathrm{g} / \mathrm{ml}\end{array}$ & & 9 \\
\hline 10 & Safan Ashour et al & $0.4-12.3 \mu \mathrm{g} / \mathrm{ml}$ & & 11 \\
\hline
\end{tabular}

\section{CONCLUSION}

A simple, precise, sensitive, accurate and easy spectrophotometric method for the determination of pentoprazole was developed and validated. The method developed was found to be advantageous with respect to its accuracy, compared to other methods reported so far. The method was found to be economical and can be used as an alternative method for the determination of bulk samples and tablets.

\section{ACKNOWLEDGMENT}

The authors thank the Principal and management of M V G R College of Engineering, Vizianagaram-535005 for providing necessary facilities and for their constant support \& encouragement.

Financial support and sponsorship: NIL

\section{CONFLICTS OF INTEREST}

There are no conflicts of interest

\section{ABBREVIATION USED}

Maharaj Vijayarama Gajapathi Raj College of engineering.

\section{REFERENCES}

1. Prescribing Info". Protonix package insert. Retrieved November 3, 2015

2. Richardson, Paul; Hawkey, Christopher J.; Stack, Dr William A. (2012-11-29). "Proton Pump Inhibitors". Drugs 56 (3): 307-335. https://doi.org/10.2165/ 00003495-199856030-00002; PMid:9777309.
3. Herzig, SJ; Doughty, C; Lahoti, S; Marchina, S; Sanan, N; Feng, W; Kumar, S 2014, Acid-suppressive medication use in acute stroke and hospital-acquired pneumonia Annals of Neurology 76(5):712-8. https://doi.org/10.1002/ ana.24262; PMid:25164323 PMCid:PMC4214881.

4. Research, Center for Drug Evaluation and. "Postmarket Drug Safety Information for Patients and Providers - FDA Drug Safety Communication: Possible increased risk of fractures of the hip, wrist, and spine with the use of proton pump inhibitors".

5. Rajnish Kumar, Harinder Singh and Pinderjit Singh. Development of UV spectrophotoemrtic method for estimation of pentoprazole in pharmaceutical formulations, Journal of Chemical and Pharmaceutical Research, 2011,3(2):113-7

6. Okram Zenita Devi and Kanakapura Basavaiah, Validated spectrophotometric determination of pentoprazole sodium in pharmaceuticals using ferricchlorie and two chelating agents, International Journal of chem. Tech Research, 2010,2,1,624-32

7. Moustafa AA. Pharm Biomed Anal J. 2000,22(1),45-58. https://doi. org/10.1016/S0731-7085(99)00275-7.

8. Ncilay SÜSLÜ, Sacide ALTINÖZ, Emine YILDIZ, FABAD, Determination of pentoprazole in tablet dosage form by spectrophotometric method, J. Pharm. Sci., 28, 85-92, 2003 RESEARCH ARTICLES

9. Basavaiah, K., Anil kumar, U.R., Sensitive spectrophotometric methods for the determination of pentoprazole sodium in pharmaceutiocal formulations using bromate-bromide, methyl orange and indigo carmine as reagents, Indian journal of Chemical technology, 2007,14,611-5.

10. Baraka M, El-Sadek Mohamed E, Lobna M. Abdel-Aziz, Samar S. El-Bermawi, Validated spectrophotometric determination of pentoprazole sodium in tablets using in 2,4-dinitrofluorobenzene through nucleophillic substitution reaction, Asian Journal of Pharmaceutical Analysis and Medicinal Chemistry, 2014,2,1,26-36.

11. Safwan Ashour and Roula bayram, new spectrophotometric method for the determination of pentoprazole in tablets using 1,2-naphthaquinone-4sulphonic acid as chromogenic reagent, R.J.Of. Aleppo. Univ, 2012, 85.

12. M. Purushotham reddy, G. Ramachandra reddy and N. Rami reddy, A simple spectrophotometric determination of pentoprazole in pharmaceutical formulations, Chemical Science Transactions, 2014;3(1),203-12.

13. Sahdev Chosla, Vishal bhatt and Hiren Kadikar, Development and validation of UV spectrophotometric method for the simultaneous determination of pentoprazole and levosulpiride in pharmaceuti.cal dosage form, American Journal of Pharmatech Reserach, 2013, 3, 1.

14. Jigar Pandya, Mr. Sagar Solanki, Dr. Mandev Patel, development and validation of differential spectrophotometric method for determination of 
pentoprazole in tablet dosage form, JPSBR: Volume 2, Issue 1: Jan Feb 2012;2(1): 2-4

15. Kalaichelvi1. R, Fatima rose. M, vadivel. K, Jayachandran. E, Simple extractive colorimetric determination of pentoprazole sodium by acid dye complexation method in solid dosage form, International journal of Chemistry

research, 2010;1:6-8.

16. Indian Pharmacopeia, 2014, $7^{\text {th }}$ Edition.

\section{SUMMARY}

- A novel chromogen for the spectrophotometric determination of pentoprazole sodium in pharmaceutical formulations was developed.

- The mixed reagent is prepared by mixing aluminum chloride solution with eriochrome cyanine $r$

- When the drug on treatment with the reagent a stable clear and instantanoues red colour product developed, showed wavelength maximum at $533.5 \mathrm{~nm}$.

- Beer's law obedience was found to in the range 3.2-12.8 microgram/liter

- The method was validated and found to

\section{About Authors}

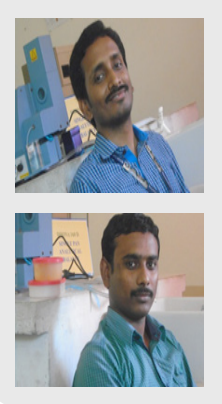

G V S R Pavan Kumar: $\mathrm{He}$ is presently working as Assistant Professor in the Department of Chemistry at MVGR College of Engineering (A), Vizianagaram. He had done his M.Sc., in chemistry with Analytical Chemistry as special subject, pursuing his PhD from Acharya Nagarjuna University. He published 25 research papers in national and international journals.

K Srinivasa Rao: He had done his M.Sc., in Chemistry with Analytical Chemistry as Special Subject. At present he is working as lab demonstrator in the Department of Chemistry at MVGR College of engineering (A), Vizianagaram.

Cite this article: Pavan Kumar GVSR, Srinivasa Rao K. Aluminium-eriochrome cyanin R, a novel chromogen for the spectrophotometric determination of pentoprazole sodium. Indian J of Pharmaceutical Education and Research. 2017;51(2S):S34-S39. 